\title{
How bees distinguish colors
}

This article was published in the following Dove Press journal:

Eye and Brain

II March 2015

Number of times this article has been viewed

\section{Adrian Horridge}

Biological Sciences, Australian National University, Canberra, $\mathrm{ACT}$, Australia
Correspondence: Adrian Horridge 76 Mueller Street, Yarralumla, ACT 2600, Australia

Email horridge@netspeed.com.au
Abstract: Behind each facet of the compound eye, bees have photoreceptors for ultraviolet, green, and blue wavelengths that are excited by sunlight reflected from the surrounding panorama. In experiments that excluded ultraviolet, bees learned to distinguish between black, gray, white, and various colors. To distinguish two targets of differing color, bees detected, learned, and later recognized the strongest preferred inputs, irrespective of which target displayed them. First preference was the position and measure of blue reflected from white or colored areas. They also learned the positions and a measure of the green receptor modulation at vertical edges that displayed the strongest green contrast. Modulation is the receptor response to contrast and was summed over the length of a contrasting vertical edge. This also gave them a measure of angular width between outer vertical edges. Third preference was position and a measure of blue modulation. When they returned for more reward, bees recognized the familiar coincidence of these inputs at that place. They cared nothing for colors, layout of patterns, or direction of contrast, even at black/white edges. The mechanism is a new kind of color vision in which a large-field tonic blue input must coincide in time with small-field phasic modulations caused by scanning vertical edges displaying green or blue contrast. This is the kind of system to expect in medium-lowly vision, as found in insects; the next steps are fresh looks at old observations and quantitative models.

Keywords: vision, honey bee, visual processing, optimum system, picture sorting

\section{Introduction}

Bees certainly detect and visit colored flowers on a background of mixed browns and greens. They also learn and distinguish landmarks, partly by their color, but despite a century of descriptions of the performance, it is not known what kind of mechanism is at work. One may calculate or make direct measurements of the intensity of the stimulus at each of the three types of photoreceptor cells in each ommatidium, but the distribution of photon captures tells nothing about subsequent processing. Similarly, electrophysiology tells a great deal about the responses of neurons within the optic tracts to different colors, but the electrical activity and neuronal anatomy cannot be interpreted in terms of choices or decisions because neurons are orders of magnitude faster and more complex. To discover what bees actually detect, learn, and recognize in colors, direct tests of trained bees are essential.

Almost exactly a century ago, von Frisch ${ }^{1}$ trained bees to come to colors versus various shades of gray. He publicly demonstrated his bees trained to blue, and published numerous test results. He inferred color vision because his bees discriminated blue, black, white, and yellow from all shades of gray. This was a standard test for defects in 
human color vision but not an analytical tool to reveal inputs or mechanisms. However, his bees could not distinguish between the gray levels when trained on a mid-gray paper and could not distinguish green or greenish-blue from all shades of gray. At the time, Hess ${ }^{2}$ found that bees trained on yellow versus various gray levels had learned something but apparently, nothing about color. After the death of Hess in 1923, the test designed to detect color defects in human vision was accepted as scientific support for the popular belief that bees could detect, learn, recognize, and discriminate between different colors. This inference was an error.

A few anomalies appeared in the literature over the past century, and the inputs used to discriminate colors remained unknown. A part of the problem was the difficulty of calibrating the emission spectra of experimental colored surfaces and the spectral sensitivity of the three types of bee photoreceptors. However, that can now be done (Table 1). A more fundamental delay was caused by a tendency of human investigators to measure the performance of bees in their familiar tasks, at which the bees were always successful. This work produced excellent measurements of the resolution of small differences of color or the effect of retraining on a second or third color, and so on, but performance gave little information about mechanism - from the speed and noise of your motorcar, it is hard to infer the presence of the piston, cylinder, or spark. Experimental tests are required to deduce the causative mechanism, often by looking for the causes of failures. So it was with bee vision.

Three possible inputs have already been identified, one of which is tonic blue content, and the others are phasic responses of the green and blue receptor pathways. When bees distinguish between black and white, ${ }^{3}$ they detect two simple cues, the position and measure of blue content (related to intensity at blue receptors, summed over each eye

Table I Relative receptor excitations by the different papers relative to the white paper (100\%), and contrasts between some pairs of papers

\begin{tabular}{lll}
\hline Canson colored papers & Blue receptor & Green receptor \\
\hline Hemp 374 & 34.2 & 56.3 \\
Ultramarine 590 & 33.8 & 20.7 \\
Billiards green 576 & 17.0 & 22.3 \\
Buff 384 & 25.7 & 41.7 \\
Blue 595 & 54.2 & 40.0 \\
White copy paper & 100 & 100 \\
Gray (40\% black) & 60 & 60 \\
Contrast 374/590 & 0.006 & 0.46 \\
Contrast 384/595 & 0.36 & 0.02 \\
\hline
\end{tabular}

Notes: The responses of the bees to contrast saturated near values of 0.4 in bright light. The Canson papers were kindly calibrated by MV Srinivasan and SW Zhang. separately), and the positions and a measure of modulation of green receptors (related to summed green contrast at vertical edges). The angle between these two cues provided a measure of angular size. Black, white, and gray were distinguished by measures of modulation at edges, not by contrast alone. ${ }^{3}$ When bees distinguished between equal vertical and horizontal gratings with equal blue content and no green contrast, they were obliged to use the next preferred cue, the difference in modulation of the blue receptors. ${ }^{4}$ The same methods of analysis have now been employed to discover the inputs that bees use to distinguish between colors.

In the following experiments, ultraviolet (UV) was excluded to reduce the number of variables, so the detection of color could depend on phasic as well as tonic responses of green or blue receptors. So, four independent variables are possible inputs. Here, "phasic" is intended to mean the modulation of receptor responses as bees in flight scan across vertical edges, and "tonic" refers to maintained responses to photon flux. Modulation is a measure of the dynamic response of the receptors as the bee scans across a vertical edge.

\section{Materials and methods}

The way to train honey bees and then test their preferences in forced choices, with carefully selected pairs of test patterns, has been described many times..$^{3-9}$ The bees (Apis mellifera Linnaeus) flew freely from an isolated neighboring hive for 9 months of the year in Canberra. Ten to 15 bees were individually marked with artists' colors, and only these were allowed to enter the apparatus (Figure 1). A larger group

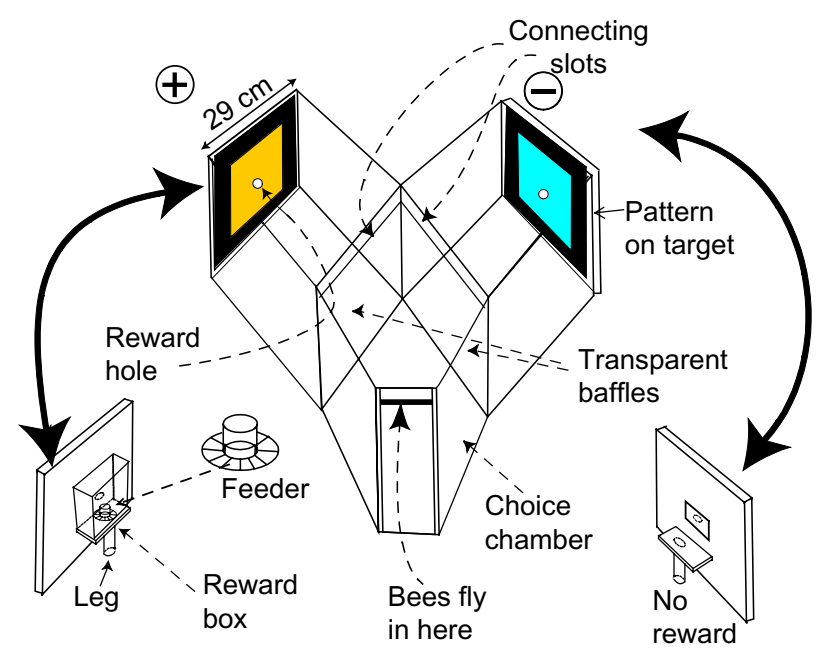

Figure I In this apparatus, bees entered the chamber at the front, and from there, they made an informed choice between two targets. They selected one side, passed through the narrow horizontal slot over one of the transparent baffles and reached the reward hole. When satisfied at the feeder, they exited by the way they came. To make the bees look at the patterns and learn something, the reward with its display changed sides every 5 or 10 minutes. 
would risk visual contact between bees. The reward was a solution of cane sugar that was adjusted in strength between $2 \%$ and $7 \% \mathrm{w} / \mathrm{w}$ so that recruits were not attracted but marked bees continued to return for more. The pattern, with the reward, changed sides every 5 minutes to force bees to look at the patterns and to equalize any chance of spurious cues from unequal olfactory cues or side preferences. Spurious results caused by odors are easily detected by testing with two clean identical targets or by testing with reward on both sides. The reward was provided in the test phase, otherwise bees continued to search. Test phases lasted for 5 minutes, separated by continued training for 20 minutes. At a different time, the test was repeated with the two sides reversed, and each test was followed by a different test. The many different tests implied a long gap before any one test was repeated, so the bees learned only the training display. The process of training interrupted by tests continued all week until sufficient choices accumulated.

The apparatus (Figure 1) was made with wooden sides and a transparent top of polycarbonate sheet that excluded UV light. A transparent plastic roof above provided further protection from UV light. The floor and inside walls of the apparatus were painted white.

The Canson colored papers were purchased from art supply shops and can be ordered online (http://www.cansoninfinity.com/en/values.asp). To avoid confusion regarding bee colors and alternatives in the literature, the manufacturer's color names were used in this paper. Details of the stimulus to the blue and green receptors reflected from these papers are given in Table 1. Methods of calibration have been given in the literature. $5,6,8$

Each test was a forced choice between two unfamiliar targets, so theoretically the score should be either $100 \%$ (can do) or $50 \%$ (fail). Therefore it is hard to justify that differences between intermediate scores in tests (based on four unknown variables) have any validity. Therefore the tests were designed so that the results were unambiguously pass or fail, and a variety of different training experiments supported each other, with numerous tests in each training experiment so that the trained bees saw each test only once or twice in each day. The conclusions were deduced by logic based on whether the bees could or could not pass the tests in each experiment.

\section{Statistics}

Scores at each test were presented as the percentage of correct choices and the number of choices by the group of 12-15 trained bees. It is important to understand that the result of each test was a unique piece of data for that pair of test patterns and was unrelated to the other tests in that experiment. The test scores were not comparable with each other because each was a forced choice between two unfamiliar targets, so in an ideal world, the bees would be $50 \%$ or $100 \%$ correct, eg, fail or pass. Therefore, in each test, only a significant pass or fail was required, so we need to know whether each test score was theoretically different from $50 \%$. Only minimal statistics were required for each test. Every effort was made to design test patterns that gave clear yes/no answers.

With continued training and other tests intervening, each test was continued until 100-200 choices had been made. Because the data are frequencies, standard deviation (SD) was calculated from the formula

$$
\mathrm{SD}=\sqrt{ }[\mathrm{p} \cdot(1-\mathrm{p}) / \mathrm{n}]
$$

where $\mathrm{p}$ is the measure of probability of a correct response, and $\mathrm{n}$ is the number of observations. ${ }^{9}$ This formula is valid when the choices of the bees are independent and the scores have no trend. As a quick rule of thumb, a score of more than $0.57(57 \%)$ for $n=200$, or a score of $0.60(60 \%)$ for $n=100$ was then more than two SDs greater than chance $(P<0.05)$, which was acceptable. When for example, the score was 0.62 $(62 \%), n=100$, which was acceptable.

In the more exact method, we wish to reject the null hypothesis that the observed score is not significantly different from $50 \%$, in a random sample from a binomial distribution. An exact $P$-value was computed using a binomial test, without any normal assumption or central limit theorem claim, with an estimate of the bias and a standard test to reject the hypothesis that the bias was 0.5 . The test was two-sided because values on either side of 0.5 occurred. In Figure 3B, we have $\mathrm{n}=62 \%$, so $P$ (estimated bias -0.5$)>0.12$, where the probability is taken with respect to a binomial distribution with bias 0.5 and $n=100$. From a table of $P$-values, $P=0.020$ $(2 \%)$, which is acceptable.

A poor score may mean poor learning of features appearing in the test, or little to distinguish between them in the test patterns. In the most informative tests, when the bees failed, the missing input could be supplied in a further test. The training and test scores can be improved by longer training periods. In every experiment, the interpretation depends on logical deduction from the successes or failures in the tests.

\section{The setting and illustrations}

For each experiment, it is essential to refer to the corresponding illustration while reading the text. Two training patterns are shown at the top of each illustration, with the rewarded 
one on the left marked by $(+)$, followed by a set of test patterns, with corresponding scores and a small black histogram. Each illustration should be read from the top down considering each successive test, but actually tests were interleaved and most experiments took many days. Conclusions were deduced logically from results of tests.

In previous work, ${ }^{3-5,7}$ the bees usually learned only to avoid the unrewarded pattern because they learned by trial and error; so they remembered their errors from the training. When they returned for more reward, they recognized the parameters to avoid. When they needed to compare two targets, they learned inputs from both. In order of preference, they learned a few simple cues from the external parameters for the particular training patterns on hand and recognized these cues when they returned. They did not learn the whole training patterns and then compare them with the test patterns. ${ }^{10}$

\section{Results}

\section{Bees measure the blue content}

A vertical bar of blue on a black background was readily discriminated from a square of blue on black (Figure 2A), although with two black/blue vertical edges and two black/ white ones, modulation at vertical edges was the same on the two targets. In the training, modulation learned at one target was unlearned on the other. The trained bees failed to distinguish between the rewarded target and plain black one (Figure 2B), so whatever they learned was on the unrewarded target. In a test with the unrewarded target versus plain blue, they avoided the larger area of blue and chose the previously unrewarded target (Figure 2C). In a test with buff on gray versus blue on gray, which were equiluminant for the green receptors (Table 1), they avoided the greater blue content (Figure 2D), but with hemp on gray versus ultramarine on gray, which are equiluminant for the blue receptors, they were lost (Figure 2E), showing that a blue difference was essential. To the trained bees, plain gray had more blue than hemp on gray (Figure $2 \mathrm{~F}$ ) because gray (40\% black) contains more blue than does hemp (Table 1). Finally, the trained bees were tested with plain gray versus two vertical black bars on gray (Figure 2G) to show they had not learned the vertical edges of the unrewarded target. They had learned only to avoid the greater content of blue (Figure 2C).

Blue is the preferred input for bees, ${ }^{11}$ and the new finding is that blue content is measured. In all experiments on bee color vision, therefore, blue content will be a preferred input and could be measured. So, to make further headway in understanding bees' recognition of color, differences in the

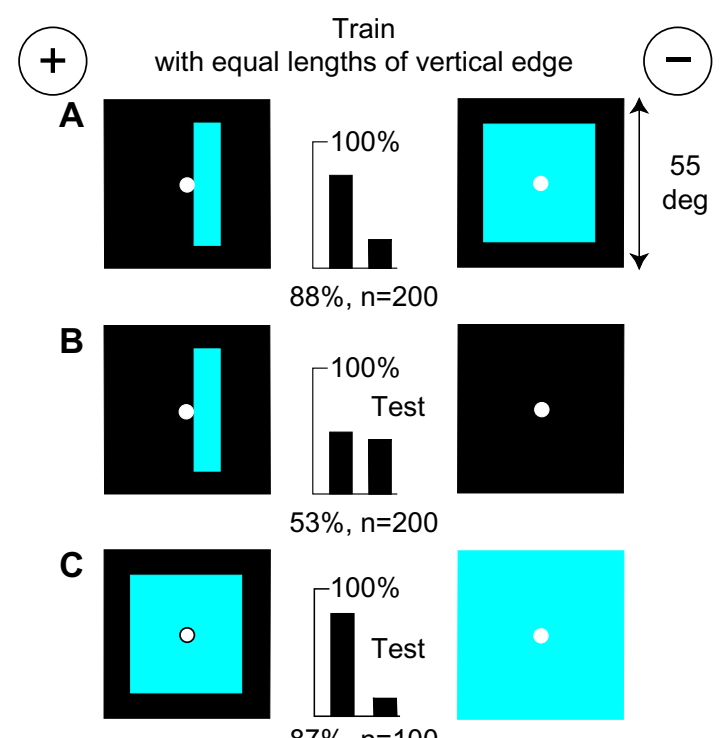

D

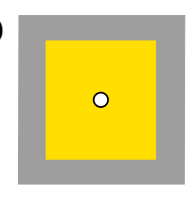

$87 \%, n=100$

E

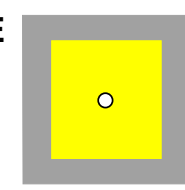

$86 \%, n=100$

$\mathbf{F}$
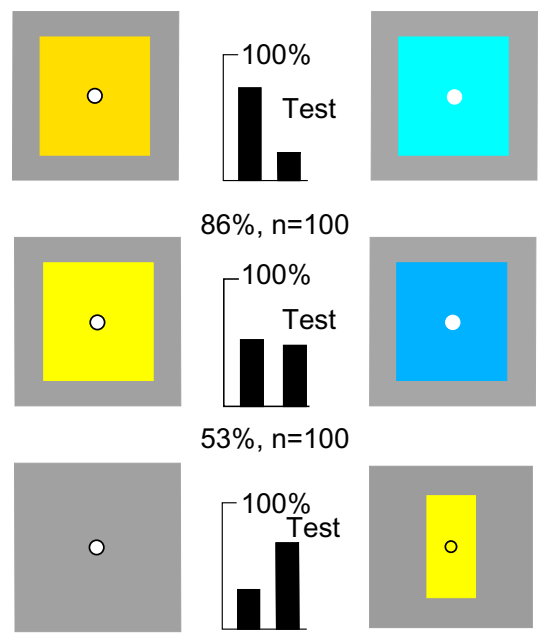

$53 \%, n=100$
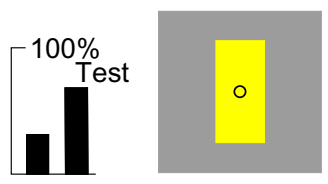

$\mathbf{G}$

$28 \%, n=100$
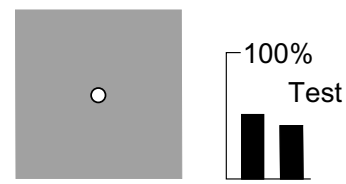

$55 \%, n=100$

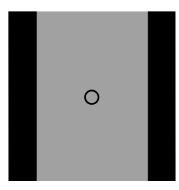

Figure 2 Bees measure the amount of blue.

Notes: (A) Training with areas of different size but equal lengths of vertical edge. (B) The trained bees did not recognize the rewarded target. (C) They reversed their preference when presented with a still larger area of blue. (D) In patterns with no difference to the green receptors, they detected the difference in blue content. (E) The trained bees failed to distinguish between targets with no difference to the blue receptors. $(\mathbf{F})$ They preferred the target where the content of blue was reduced by an area of hemp. (G) Green contrast at the vertical edges was not a significant input.

blue content of all colors, including white, must be avoided or measured.

\section{Blue bars and green contrast were retinotopic}

A new group of bees easily discriminated two vertical blue bars, one ( $8^{\circ}$ wide) half the area of the other $\left(16^{\circ}\right.$ wide $)$, 


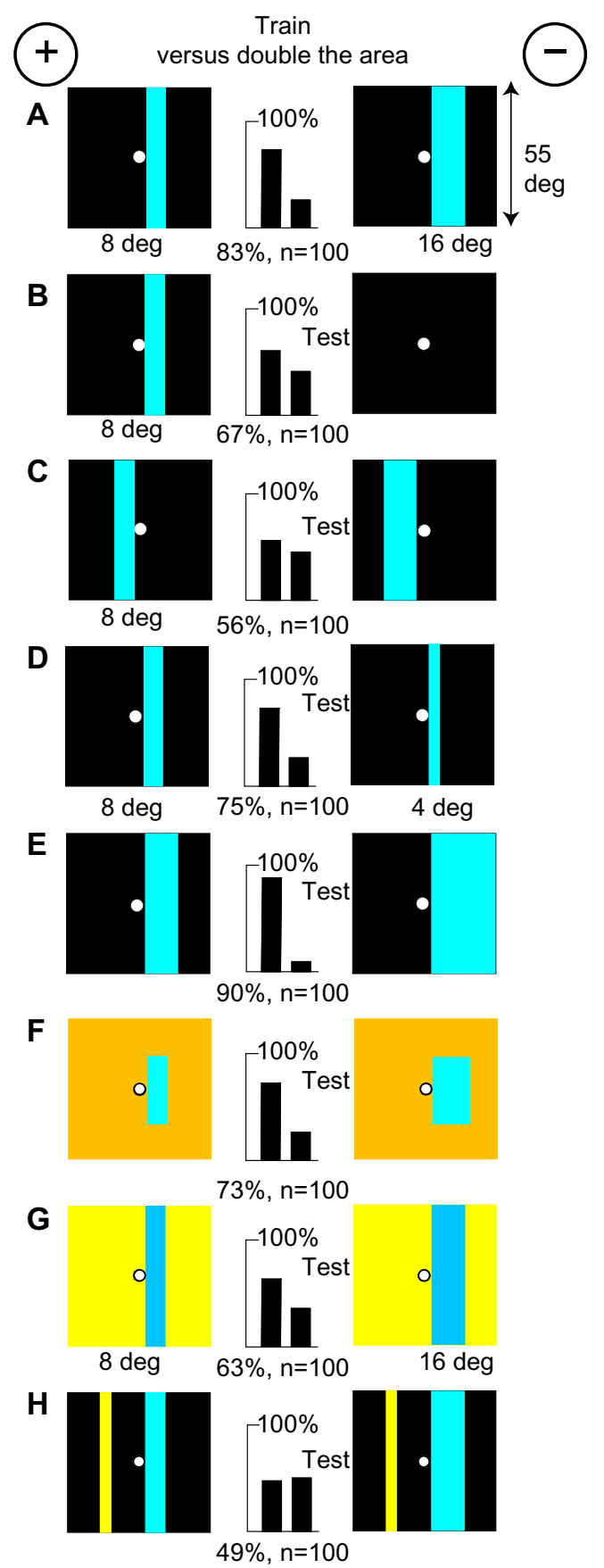

Figure 3 Position of blue is retinotopic.

Notes: (A) Training patterns. (B) The bees learned something from the rewarded target. (C) Recognition was lost when both bars were moved on their targets. (D) The trained bees distinguished the rewarded bar from a thinner one. (E) They reversed their preference when presented with an even larger area of blue. (F) They recognized the blue difference in patterns that were equiluminant for green receptors. (G) They also recognized a difference in the green modulation between the displays that were equiluminant to the blue receptors. $(\mathbf{H})$ Addition of equal green modulation to each target destroyed the discrimination.

on black backgrounds (Figure 3A). Blue and green modulation was identical on these targets, therefore was not learned. This time, because a comparison was necessary, the bees had learned something about both targets, as shown by a test versus plain black (Figure 3B compared with Figure 2B). The score was low when both bars were shifted to the left of the reward hole (Figure 3C), showing that memory of blue was retinotopic.

Next, the trained bees were tested with an $8^{\circ}$ bar versus a $4^{\circ}$ bar, both on a black background (Figure 3D). They preferred the $8^{\circ}$ bar, not the thinner bar, showing that the width or blue content of the rewarded $8^{\circ}$ bar had been measured. On the other hand, when tested with a $16^{\circ}$ bar versus a $27^{\circ}$ blue panel, they avoided the larger area (Figure 3E), suggesting that they selected the best approximation to the training pattern.

The trained bees were tested with two smaller blue areas, with the same widths as in the training, on a buff background (Figure 3F), which were equiluminant to the green receptors. As expected, they avoided the greater blue content. Because there was no difference to the green receptors and equal lengths of vertical edge, the cue must have been the content of blue. From all this, we can infer that blue content was a measure of brightness and area.

Next, green contrast was also identified. The trained bees distinguished very well between ultramarine bars $8^{\circ}$ - and $16^{\circ}$-wide against a hemp background that were equiluminant for the blue receptors (Figure $3 \mathrm{G}$ ), so they must have measured the width between the vertical edges of each bar. Green contrast was an essential part of the recognition process because discrimination was lost in the confusion when an equal strong green contrast was added to both targets (Figure 3H). Other experiments (Figure 4) showed that the width between green receptor modulation at vertical edges was always a preferred input when available, but green color content was never learned (Table 2).

\section{Vertical hemp bars on black were distinguished by width}

A group of bees was trained to distinguish between a vertical hemp bar (subtending $8^{\circ}$ by $55^{\circ}$ ) versus a similar wider hemp bar $\left(16^{\circ}\right.$ by $\left.55^{\circ}\right)$, each on a black background (Figure $4 \mathrm{~A}$ ). Despite appearances to humans, the wide bar displayed to bees twice the amount of blue as the narrow one (Table 1), but both targets were near black for the blue receptor, so blue content was low and no longer the preferred signal. The two vertical outside edges and two vertical boundaries on the targets were the same so that the bees could not detect a quantitative difference in modulation of green or blue receptors by scanning in the horizontal plane. Nevertheless, they learned quickly, achieving a high score. When each of the bars was moved to the left of the reward hole, discrimination failed (Figure 4B), showing that the memory was retinotopic. 


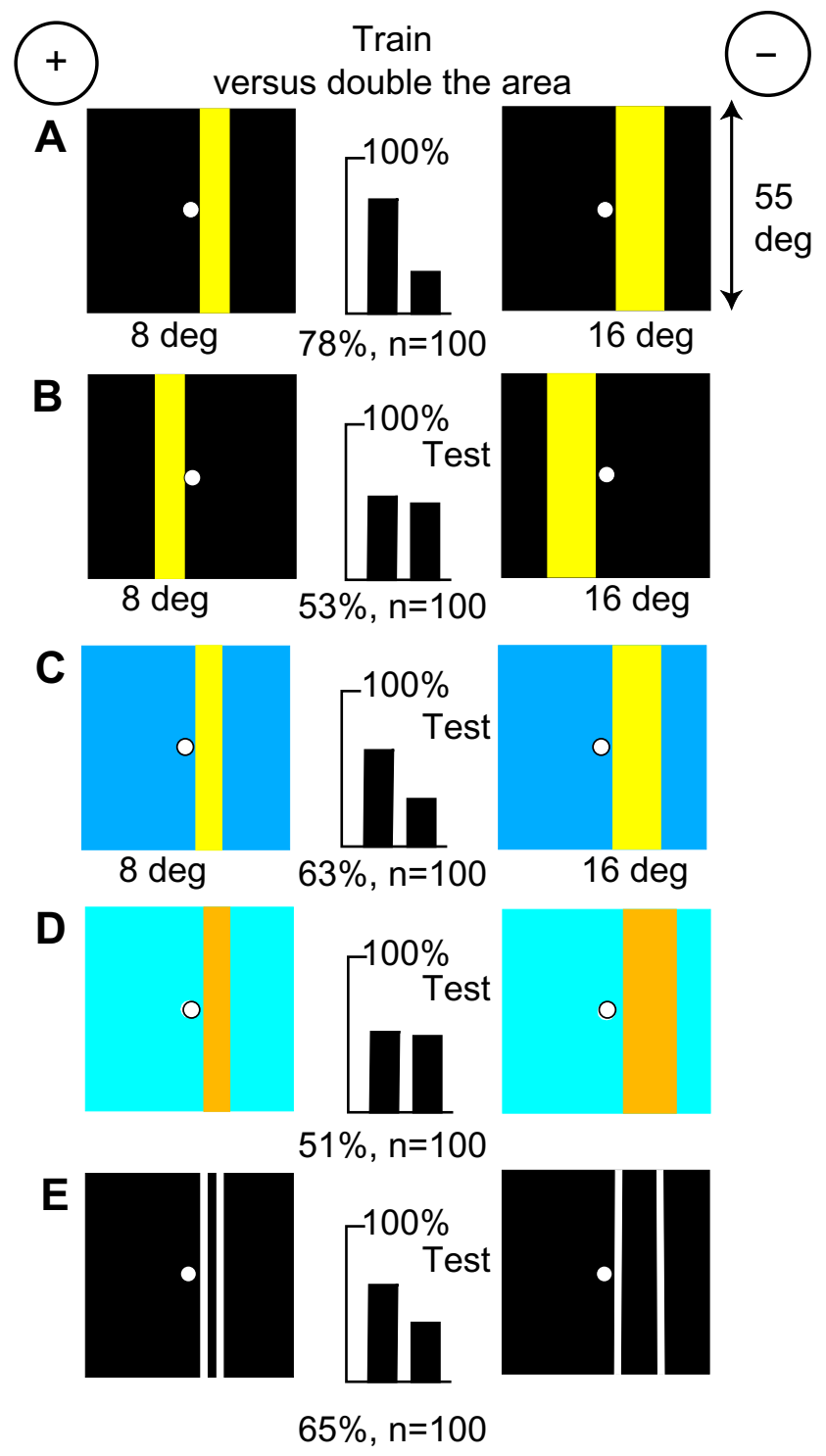

Figure 4 Hemp bars on a black background were distinguished by position and width of green modulation.

Notes: (A) Training patterns. (B) Moving the bars spoiled the discrimination. (C) Making the patterns equiluminant for the blue receptors made little difference. (D) Making the patterns equiluminant for the green receptors spoiled the discrimination. (E) The bees distinguished the separation between the white lines corresponding to the edges of the training bars.

When tested with an $8^{\circ}$ hemp bar versus a $16^{\circ}$ hemp bar on an ultramarine ground (with no difference to the blue receptors), the score was little affected (Figure 4C), showing that they had not learned a blue difference. By this time, most of the possible inputs had been excluded. When tested with buff bars on blue with no green contrast (Figure 4D), discrimination failed, showing that all the learning had been in the green receptor pathway. This was confirmed by showing that the trained bees measured the width between thin white lines $\left(1^{\circ}\right.$ wide) in the positions of the green contrast at the edges of the bars in the training patterns (Figure 4E).
The most preferred and strongest signals were therefore the green contrast at the vertical edges. The bees compared the widths of the hemp bars, not the color content. Hemp bars were treated quite differently from blue bars (Figure 3 ). The result illustrates the necessity for numerous tests to discover what the bees actually detected.

\section{Black and blue were distinguished by green contrast and blue content}

A black target has strong contrast at its vertical edges for bees scanning in the horizontal plane but displays no other stimulus. The other target was blue, which is a preferred input. A new group of bees were readily trained to avoid the blue (Figure 5A) but reversed their preference when offered white (Figure 5B), which had double the blue content of the blue paper (Table 1). They were unable to distinguish between hemp and ultramarine (Figure 5C), which were equiluminant for blue-sensitive detectors. Therefore a difference in blue content was an essential part of the training. When tested with buff versus blue (Figure 5D), which were equiluminant for green-sensitive receptors, the trained bees detected the difference in amount of blue but with a weak score because the targets were equiluminant for the green receptors. Therefore blue was only a part of the input; the missing input was represented by a difference in green modulation at the vertical edges, as shown by testing with plain black versus hemp (Figure 5E). The response was as strong as in the training because the vertical edges of the black target displayed a strong green contrast against the white background, while the hemp target displayed much less green contrast against white. Both targets in Figure 5E were dark to the blue receptors (Table 1). Finally, the trained bees were tested with plain black versus a black square with a white center (Figure 5F). In this test, one target had more vertical edges that attracted the trained bees, but they also avoided the blue input from the white center, reducing the score.

\section{Green and black were distinguished by blue content and green modulation}

Bees trained to discriminate a green target from a black one (Figure 6A) have an unusual task because these are colors that normally do not attract bees. However, a new group learned rapidly. The trained bees failed to distinguish between a white square on black and the unrewarded black target (Figure 6B). They were attracted to the blue content in the white square, showing that they had learned the blue content of the green. At the same time, they avoided a very 


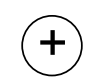

Train, black vs blue

\section{A}

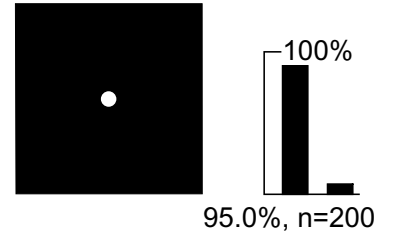

B i

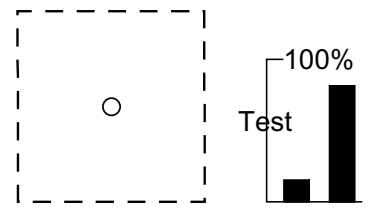

$15.0 \%, n=200$

C

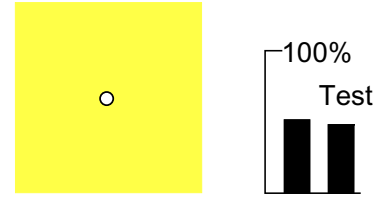

$51.0 \%, n=200$

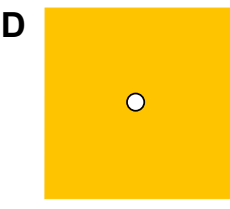

E

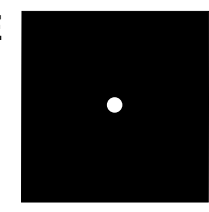

$64.5 \%, \mathrm{n}=200$

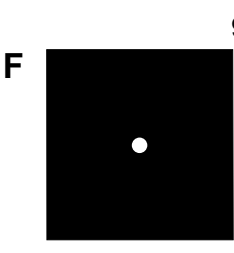

$93.0 \%, n=200$

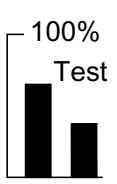

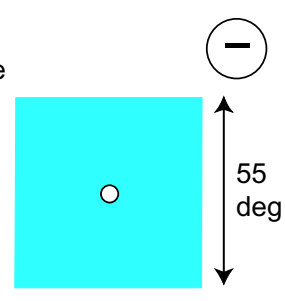
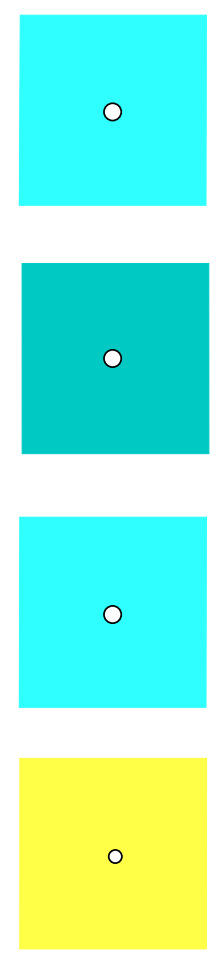

$62.5 \%, \mathrm{n}=200$

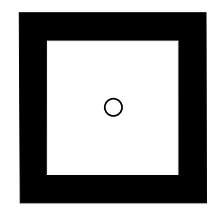

Figure 5 Bees trained on black versus blue preferred green modulation and avoided blue.

Notes: (A) Training patterns. (B) They reversed their preference for blue when presented with white, which displayed more blue. (C) With displays equiluminant to blue receptors, they were lost. (D) With no green difference, they avoided the greater blue content. (E) They preferred the strong contrast at edges of black and blue content of the hemp was small. (F) With vertical black edges on both targets, they avoided the blue content of the white square more than they were attracted by green modulation at four vertical edges.

strong source of green contrast from the vertical black edges that were displayed unequally on the two targets (Figure 6B). The trained bees much preferred green to white on black because the latter had four black vertical edges (Figure 6C). However, they abandoned the green display when offered hemp (Figure 6D) because hemp had even less green contrast at the edges, but a greater content of blue (Table 1).
Train, green vs black
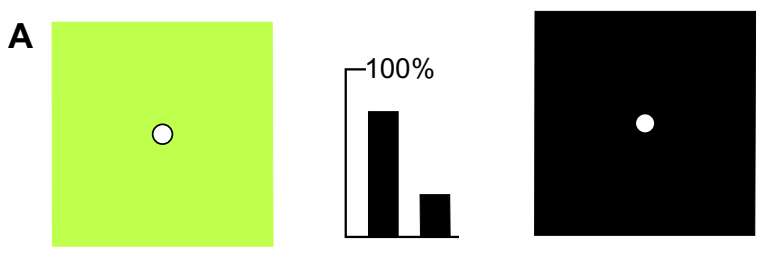

$85.0 \%, n=200$
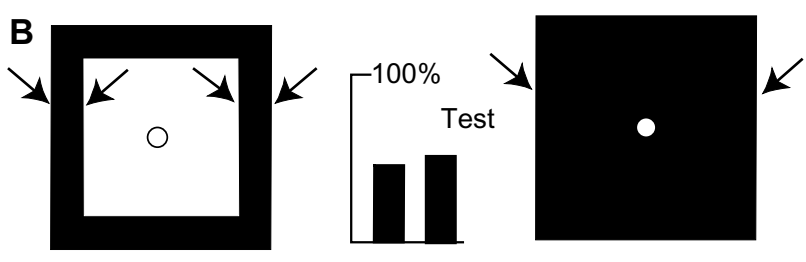

$47.5 \%, n=200$
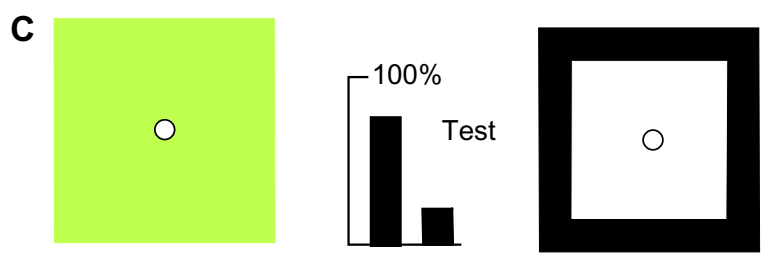

$86.0 \%, n=200$
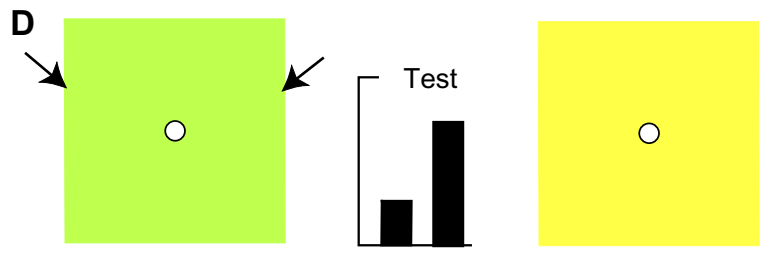

$24.5 \%, n=200$

Figure 6 The bees learned the blue content in green and avoided vertical edges of black.

Notes: (A) Train on green versus black. (B) The green contrast at vertical edges of black (arrows) was unequal but was balanced by the blue content of the white square, so the bees failed. (C) Although the white square displayed more blue than the green target, the trained bees avoided the vertical black edges. (D) They avoided the greater green contrast at the edge of green (arrows), and the hemp displayed more blue content.

In this experiment, there is abundant evidence that they measured the strong green modulation at vertical black edges, which is known to be a preferred input. They also distinguished green by the difference in blue content. In this experiment, there was no evidence that the bees detected black, green, hemp, or white as colors, but they measured green modulation at vertical edges and the blue content in white and green.

\section{Buff and blue on black backgrounds differ in content of blue}

Bees trained to discriminate buff on black from blue on black (Figure 7A) could not use green contrast at the internal vertical boundaries because buff and blue papers are equiluminant for the green receptors (Table 1), and the targets have equal outside 


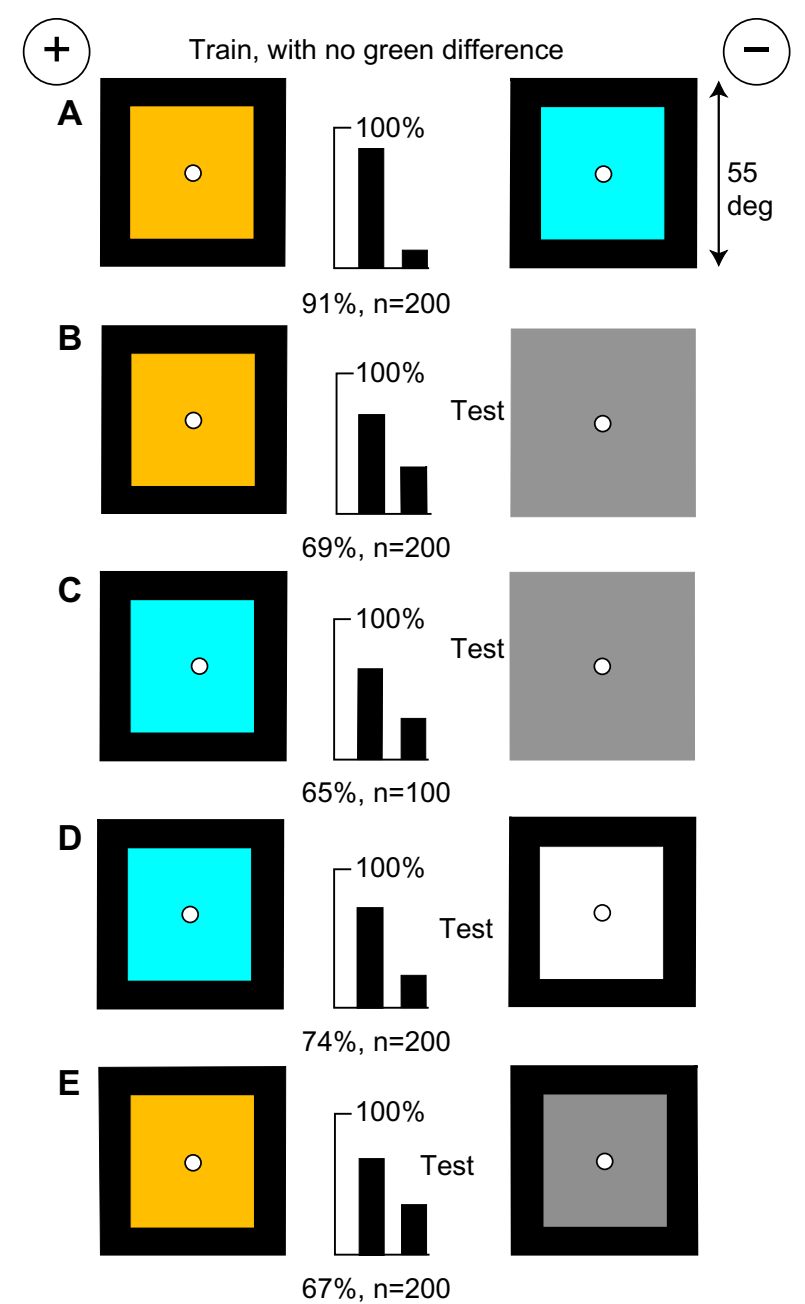

Figure 7 With no difference to green receptors, they learned blue content. Notes: (A) Training patterns. (B and C) Similar scores show that to detect the difference in blue content, they had learned both targets. (D) They reversed their preference for blue when offered white. (E) Gray ( $40 \%$ black) displayed double the blue content of buff.

edges. Nevertheless they learned remarkably well, but the effect of the limited input can be seen in the results of the tests. When tested with first one training target and then the other against plain gray ( $40 \%$ black) of twice the area of the color in the training targets (Figure 7B and C), they always avoided the larger blue content in the gray area. Similarly, the trained bees preferred blue on black to white on black, and buff on black to gray on black because they avoided the larger blue content reflected by the white or gray panels (Figure 7D and E). They learned to avoid the target displaying the most blue; the difference in blue contrast was not investigated.

\section{Hemp and ultramarine on gray were distinguished by green contrast}

Hemp and ultramarine on gray backgrounds ( $40 \%$ black) displayed no difference to blue receptors, but a new group of bees

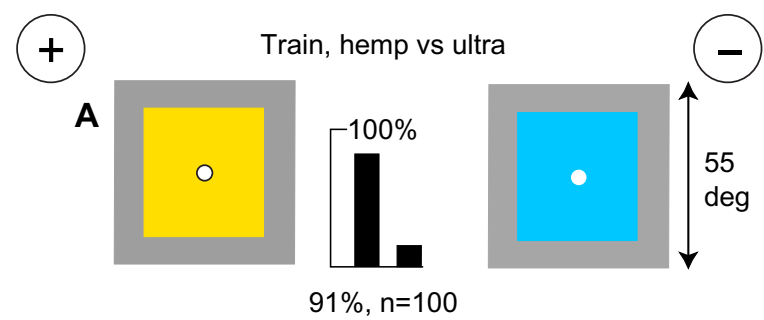

B

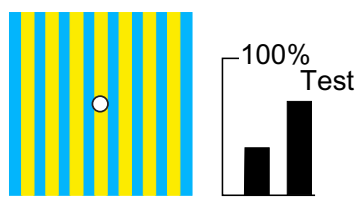

C
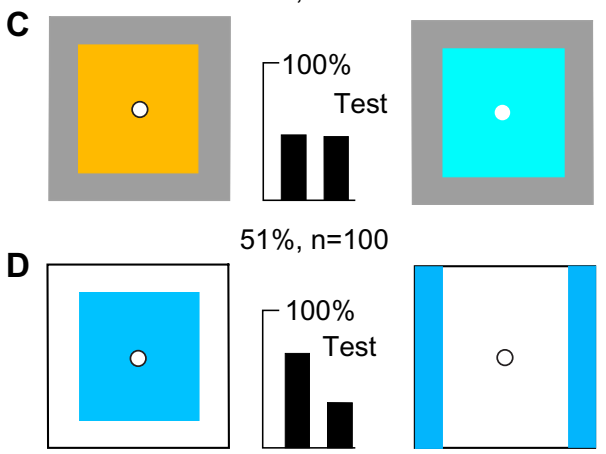

$51 \%, n=100$
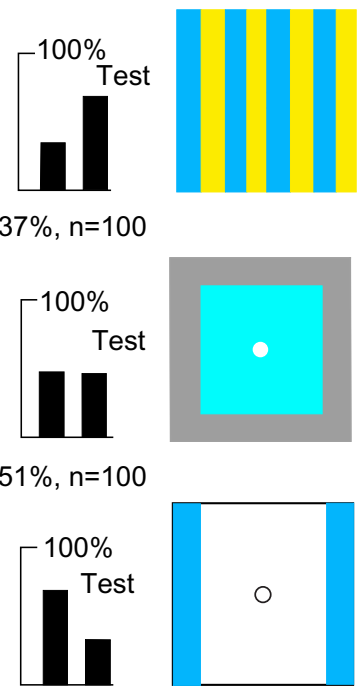

E

$78 \%, n=100$
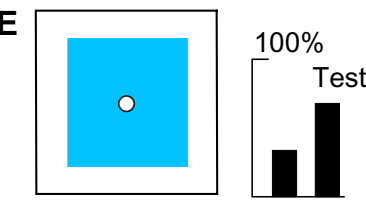

$38 \%, n=100$

$\mathbf{F}$
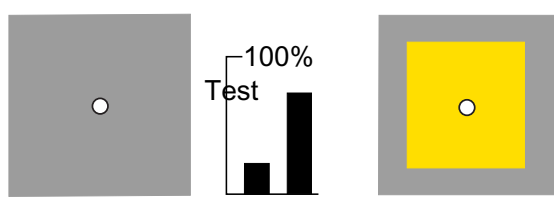

$28 \%, n=100$
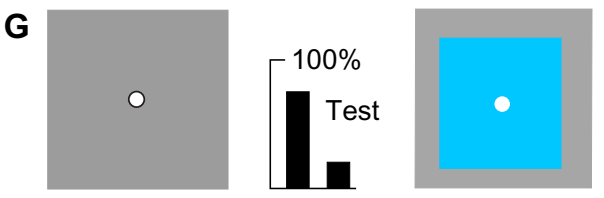

$83 \%, n=100$

Figure 8 Bees discriminated hemp from ultramarine (with no blue difference) on gray ( $40 \%$ black) backgrounds.

Notes: (A) Training patterns, with low green contrast of hemp but higher green contrast of ultramarine (Table I). (B) Tested with gratings equiluminant for blue receptors, they avoided the greater green contrast. (C) Tested with patterns equiluminant for green receptors, they were lost. (D) They avoided the extra edge length. (E, $\mathbf{F}$ and $\mathbf{G}$ ) They avoided the target with the greater green contrast.

readily learned to distinguish them (Figure 8A). When tested with two gratings with green contrast but no blue contrast, the trained bees preferred the smaller green modulation (Figure 8B). They had learned to avoid the greater green modulation where ultramarine met gray at the internal boundaries. The 
green contrast between buff and gray was smaller and in the opposite direction (Table 1), but that was not relevant for bees; only the magnitude of the modulation mattered.

The trained bees were unable to distinguish between buff and blue that were on gray backgrounds (Figure 8C) because there was no difference to the green receptors and they had not learned to look for blue. They avoided the greater length of edge between ultramarine and white (Figure 8D) but changed their preference for the ultramarine square when the alternative was a green square with less green contrast against white (Figure 8E). Tests with each training pattern versus plain gray (40\% black) showed that they had learned something from both targets (Figure 8F and $\mathrm{G}$ ) as indeed they were forced to do because in the absence of a blue difference, they had learned a measure of green modulation from each target.

\section{Ultramarine and hemp differed in green contrast at vertical edges}

A new group of bees was trained to discriminate between ultramarine and hemp (Figure 9A) that were equiluminant for the blue receptors but differed for green receptors. Blue content was therefore useless as a cue, but hemp had half as much green contrast as ultramarine against the white background of the apparatus (Table 1). The trained bees could not distinguish between blue and buff on identical gray backgrounds with no green difference (Figure 9B), showing that a difference in green or green contrast was essential. They could not distinguish ultramarine on a gray background versus hemp on a black background (Figure 9C) because contrast at the edge of the ultramarine, which was the crucial measurement, had been halved. The contrast of the hemp had not changed much, but it had acquired external black edges that were attractive.

Indeed, both colors were avoided when strongly contrasting vertical edges were available as an alternative (Figure 9D and E). When tested with plain targets of buff versus hemp, giving low contrast on a white background, they preferred the one with the more green contrast, although they hesitated to choose either of them. In the training, there was no blue difference, so the only input was the green contrast at the vertical edges. Nothing suggested that they could detect the large difference in the green content of the training targets. Comparison between this experiment and the previous one illustrates the strong influence of the background.

\section{Buff and ultramarine differed in blue content and green contrast}

These colors display a difference in blue and green content (Figure 10A), and also differences in the blue and green

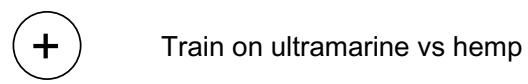

A
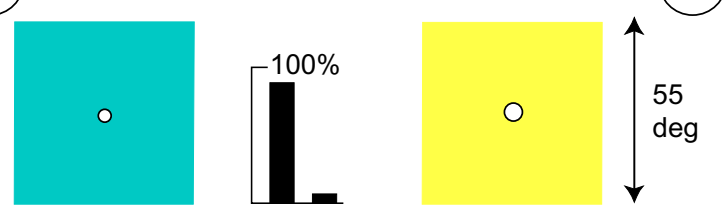

B

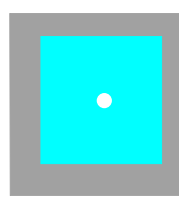

$96.0 \%, n=200$
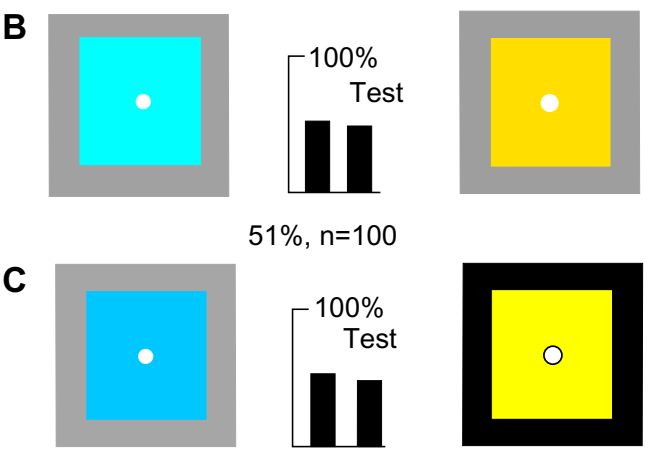

$51 \%, n=100$
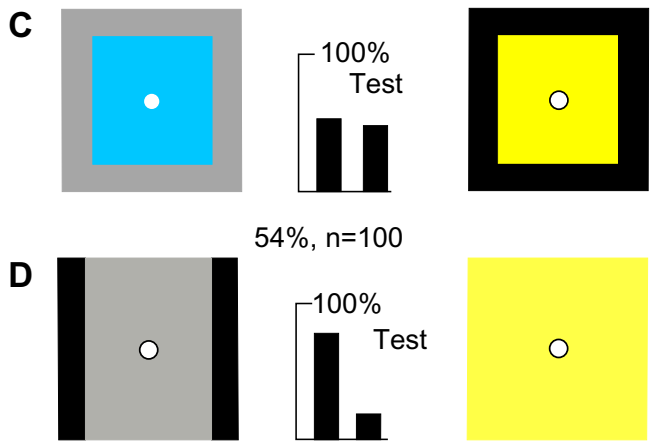

$54 \%, n=100$
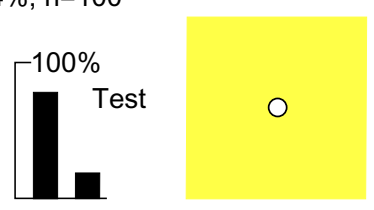

E

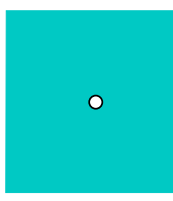

$85.0 \%, n=200$
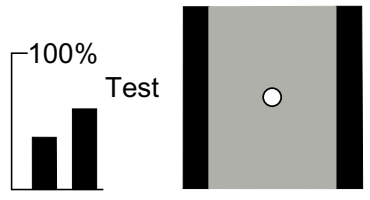

$40.0 \%, n=200$

$\mathbf{F}$
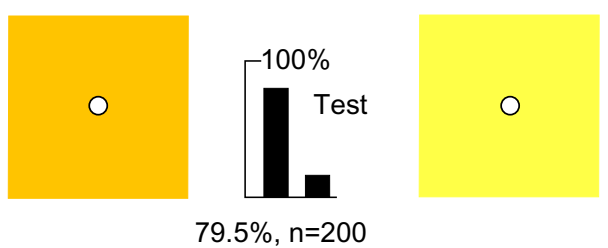

Figure 9 Bees discriminated ultramarine from hemp by the difference in green contrast at edges.

Notes: (A) Training targets. (B) In a test with blue and buff on gray, equiluminant for green receptors, they failed. (C) Discrimination between ultramarine and hemp was lost when the background changed. (D and E) Strong contrast at the edges was attractive. (F) Buff had more green contrast than did hemp at the vertical edges.

contrast at the edges, so there were several possible cues available in parallel. The new group of trained bees quickly switched their preference away from the buff when offered hemp as an alternative (Figure 10B), but they preferred hemp when it was offered versus ultramarine or blue (Figure 10C and D). Therefore, in these tests, the bees revealed that they had learned to avoid the blue content in the ultramarine.

However, that is not the whole story. The trained bees could not distinguish between buff and blue when each was presented on a gray background (Figure 10E), despite that 
there was plenty of blue difference, because these colors were equiluminant for the green receptors. The trained bees needed a difference in the position or measure of the green contrast as well as in the amount of blue because they had learned both in the training. As shown by additional tests, they consistently

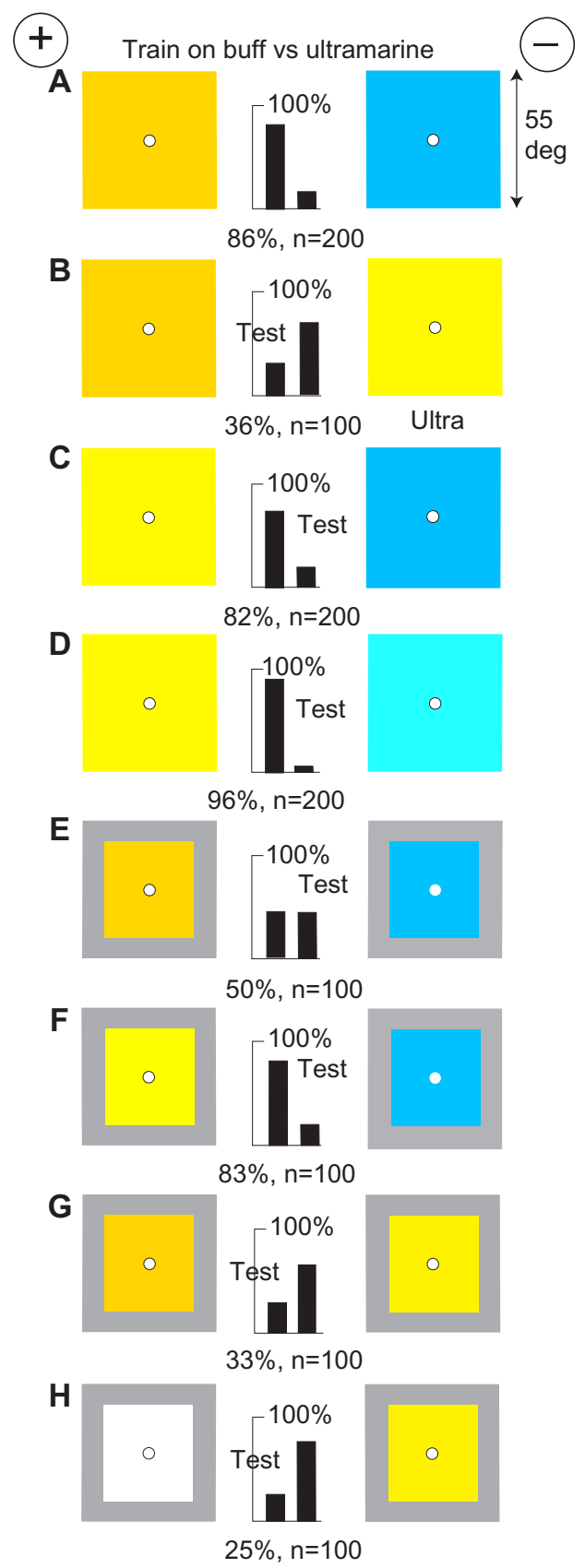

Figure 10 Two colors with contrast against white, for both receptor types, were distinguished by green contrast and avoidance of blue.

Notes: (A) Train, buff versus ultramarine. (B) They reversed the preference for buff when presented with hemp, with less blue and less green contrast against white. (C) Displays equiluminant for blue receptors were recognized. (D) Hemp with less blue than buff, versus blue gave the highest score. (E) In a test that was equiluminant for green receptors, they failed. (F) Displays equiluminant for blue receptors, on equal backgrounds, were recognized. (G) Buff displayed more blue and more green contrast than did hemp. $(\mathbf{H})$ White displayed more blue and green contrast than did hemp. avoided the greater amount of blue content when there was also a difference in the green contrast at internal vertical edges (Figure 10F-H). In general, bees used two inputs and the angle between them when these were both available. Having learned two different inputs, they required both for a full recognition.

\section{Green was distinguished from}

\section{a sequence of black, white, and gray}

A new group of bees were trained to green versus a random sequence of black, white, and gray levels (Figure 11A) and

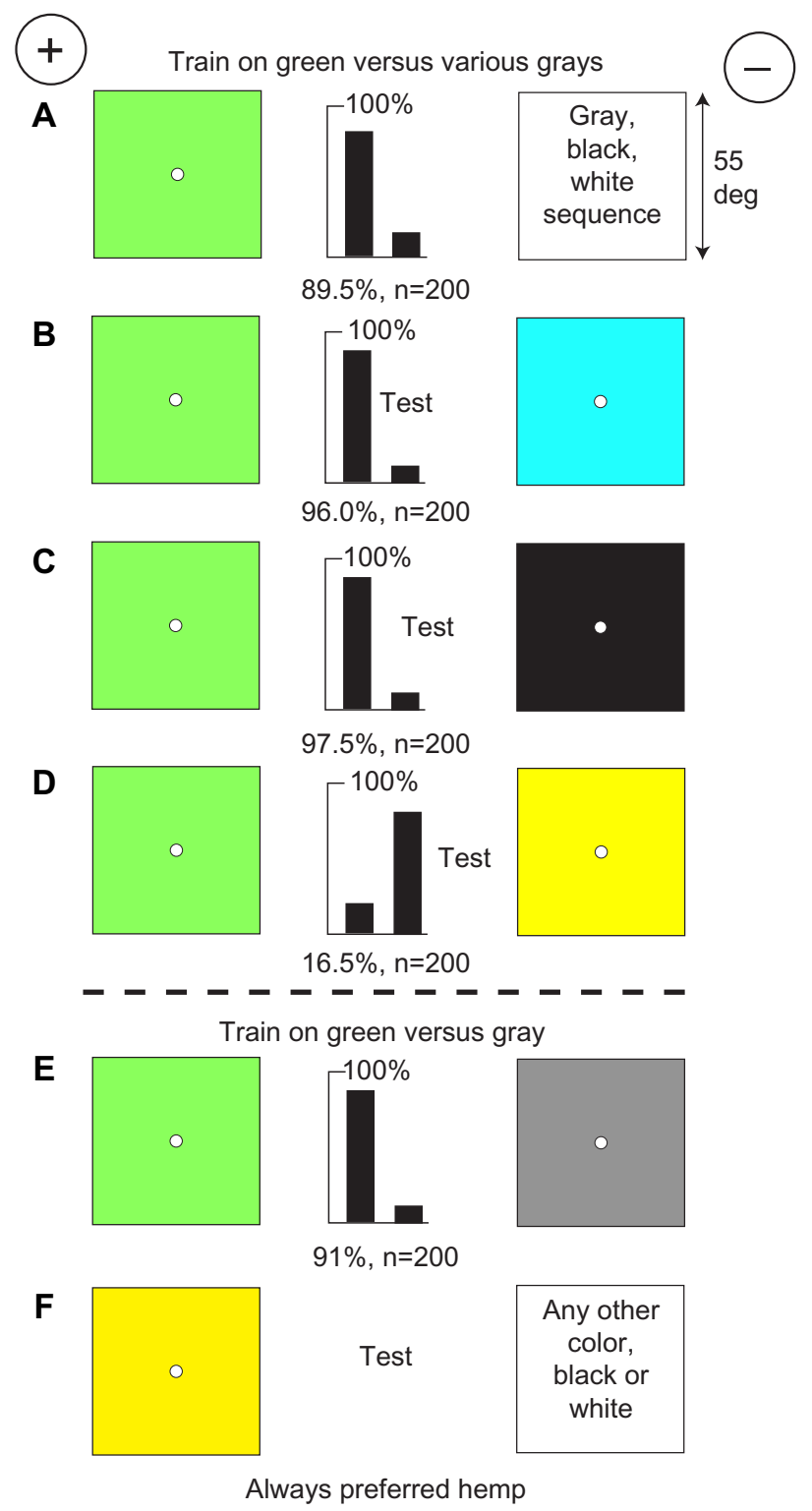

Figure I I When trained on green versus a selection of white, black, and random grays in sequence, bees did not learn green.

Notes: (A) Training. (B and $\mathbf{C}$ ) The trained bees avoided blue content and green contrast, which they were trained to do. (D) In a test versus hemp, they reversed their preference for green because they avoided blue content and green contrast. (E and F) Bees trained to green versus plain gray ( $40 \%$ black) always preferred hemp to any other color, black, or white because they had learned to avoid blue content and green contrast. 
were then given a variety of tests to discover what they had learned. In a choice between green and blue, the trained bees avoided the blue (Figure 11B), which they had learned when avoiding gray levels in the training. In a test with green versus black, they avoided the black (Figure 11C) because when training, they had also learned to avoid green contrast at the vertical edges of gray or black papers. They had not learned green as a color, however, because they preferred hemp (Figure 11D), which has less green contrast and blue content than does green. In conclusion, they had learned to avoid blue and green contrast from the gray levels in the training.

A second group of bees were trained to avoid plain gray (40\% black) and go to green (Figure 11E). In tests with hemp versus any other color, including black or white, these trained bees would always choose hemp because they had learned to avoid blue and green contrast.

\section{Bees measure blue modulation}

Blue modulation is a third preference that is observed when the preferred inputs are excluded by the design of the training patterns. The most convenient strategy to exclude the preferred cues is to train on two regular gratings of differing period (spacing) that are equiluminant for green receptors and display equal blue content (Figure 12A). A new group of bees learned rapidly, achieving a high score. When tested with the same period as in the training but with an equal number of bars, they failed (Figure 12B). Therefore, they detected the total blue receptor modulation, that is, the blue contrast summed over the total length of vertical edge, not the period or spatial frequency of the pattern. Pattern period and spatial frequency are human measures of a pattern. The bees learned the total green receptor modulation, or the blue modulation if green was not available; they did not reassemble the patterns or detect the individual bars.

Confirming that the green receptor channel was not involved, the trained bees failed to detect a hemp- or buffcolored vertical bar on a black background (Figure 12C) that was out of the sensitivity range of the blue modulation detectors. However, a vertical blue bar on a buff background, equiluminant for green receptors (Figure 12D), is easily detected because the trained bees look for the blue modulation. Similarly, two broad orthogonal buff bars $10^{\circ}$-wide on a blue background, with no green difference, were easily distinguished by the difference in blue modulation, despite that blue contrast and colors were identical (Figure 12E). Finally, the trained bees failed to distinguish training patterns presented in hemp and ultramarine with no blue difference (Figure 12F) because the cue that they had learned was lacking.

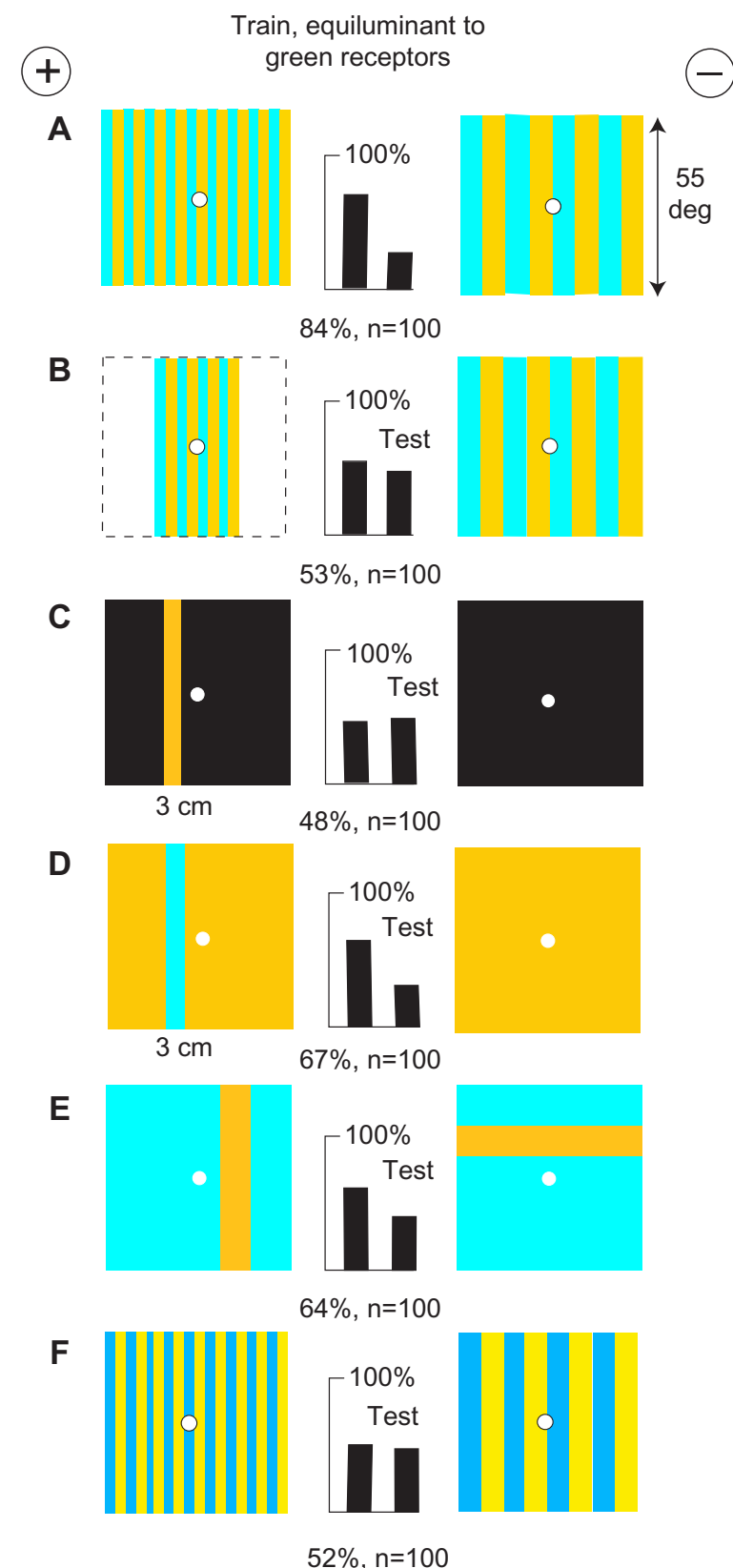

Figure $\mathbf{I} \mathbf{2}$ In a suitable task, bees learn blue modulation, not blue contrast. Notes: (A) Training on two regular gratings with no green contrast and no difference in blue content. (B) When tested with the total modulation the same on each target, they revealed that they had not learned the period of the pattern. (C) With a green difference but little blue contrast, they failed. (D) With blue contrast but no green contrast, they discriminated. (E) With no green difference and equal blue content, they preferred the greater blue modulation. (F) With no blue difference but large difference in green modulation, they failed.

\section{Blue modulation is retinotopic}

The previous experiment could not demonstrate that the display was detected as if fixed on the retina because the input - the total modulation - was a property of the whole target. However, if blue modulation is confined to a part of the display, it is learned and remembered only in that part. A new group of bees was trained to discriminate a horizontal 
from a vertical grating with no green contrast, presented in the right sides of the targets (Figure 13A). The bees could not discriminate the orientation because the orientation detectors are restricted to the green channel. ${ }^{4}$ When the gratings were moved to the other half of the targets, the trained bees failed to distinguish them (Figure 13B). The trained bees had not learned the rewarded target, as shown by their failure to recognize it versus plain black (Figure 13C). They had not learned any color difference (Figure 13D), but when tested with two regular gratings with no green contrast, they avoided the one with more blue modulation (Figure 13E), showing that they had learned to avoid the unrewarded target.

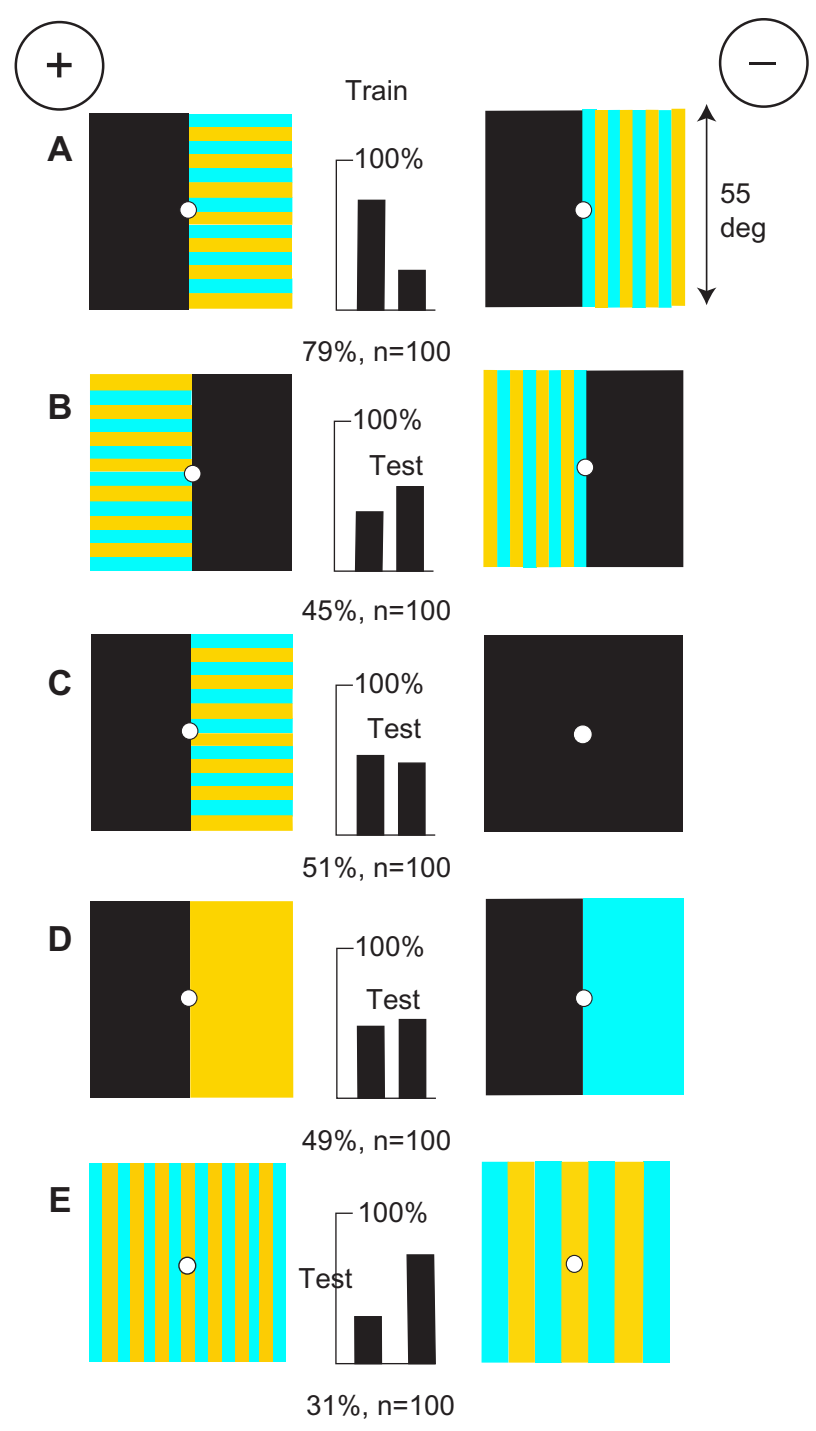

Figure 13 Blue modulation was retinotopic.

Notes: (A) Training with no green difference and similar blue content. (B) Tested on the other side of the reward hole, they failed. (C) They had not learned the rewarded pattern at all. (D) They had not learned a color difference. (E) With vertical gratings with no green contrast, they avoided the greater blue modulation.

\section{Bees measure blue in a heavily modulated pattern}

In all the experiments above, the targets were rather plain, so we turn now, to the effect of patterning. After training on two heavily modulated patterns, a hemp/white grating versus a blue/white one (Figure 14A), an interesting test

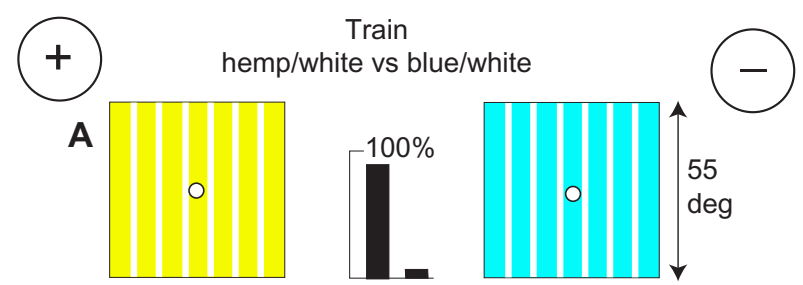

$89.0 \%, n=200$

$\mathbf{B}$
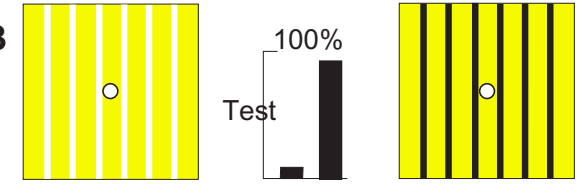

$7.5 \%, n=200$
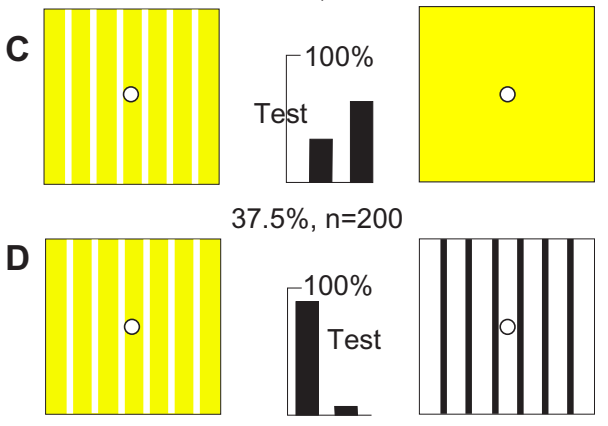

$37.5 \%, n=200$
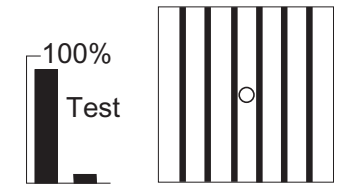

$91.0 \%, \mathrm{n}=200$

E
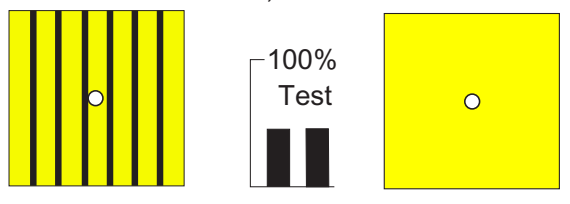

$\mathbf{F}$

$48.5 \%, n=200$
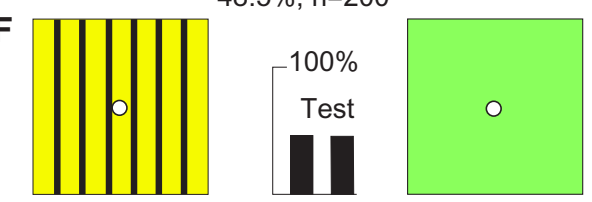

$51.0 \%, n=200$

G
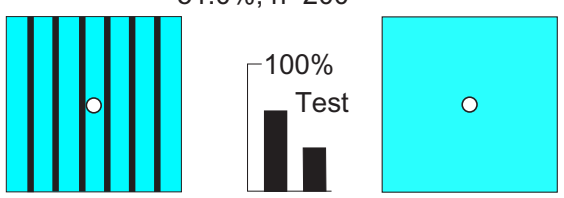

$66.0 \%, n=200$

Figure 14 The bees learned their two preferred inputs but ignored the rest of the patterns.

Notes: (A) Train on a hemp/white grating versus a blue/white grating. (B and C) They reversed their preference when presented with a hemp/black grating or plain hemp because they avoided blue. (D) With equal blue content, they avoided the greater green contrast. (E and $\mathbf{F}$ ) With no blue available, they were lost. (G) They avoided the greater blue content. 
series was obtained with the rewarded training pattern versus three other targets. Against a black and hemp grating with more green contrast but less blue, the trained bees abandoned the rewarded target to avoid blue in the white (Figure 14B). They weakly preferred a plain hemp target that had less blue (Figure 14C); however, they very strongly avoided a black and white grating with similar blue but very strong green contrast (Figure 14D). Again, the bees' response told us that they looked for a difference in blue content and green contrast.

With a hemp and black grating versus plain hemp (Figure 14E), with negligible blue on either target, the trained bees failed. They also failed with a hemp and black grating versus plain green (Figure 14F) because these had exactly the same amount of blue content (Table 1). Finally, with a blue and black grating versus plain blue with twice the blue content, they avoided the greater blue content (Figure 14G). There was evidence in the tests that they did not prefer a greater content of hemp or green (Figure 14E and F). Green modulation was similar in the training targets but the blue content differed a lot, so they had learned to avoid blue.

\section{Patterns with equal amounts of two colors}

Previous work showed that two patterns with equal amounts of two colors that are equiluminant for the green receptors (as in Figure 15A and B) are not discriminated from their reversed or mirror images unless a landmark displaying green contrast is attached..$^{4,5} 8$ Patterns equiluminant to blue receptors but differing in positions of green contrast were readily distinguished (Figure 15C). A new group of bees trained on these were obliged to learn something from each target, as shown by tests versus gray (Figure 15D and E). They avoided the greater green contrast (arrows) in hemp/ ultramarine gratings (Figure 15F) and the greater green contrast (arrows) at the vertical edges of ultramarine versus hemp (Figure 15G-I), but when the green contrast was reduced, they failed (Figure 15J and K). Replacing the central panels by gray (Figure 15L) or removing them (Figure 15M) had little effect because the bees had learned the green contrast at the outer edges of the ultramarine (arrows). When the trained bees were given a choice between different widths of green contrast, they avoided those wider apart (Figure $15 \mathrm{~N}$ and $\mathrm{O}$ ). In conclusion, in these patterns (Figure 15C), there was no blue difference and no difference in the internal green contrast at the boundary of the inner square, so the bees measured the green contrast at the outer vertical edges (arrows). The layout of the colors filling the display targets was ignored.

Patterns of several colors will often differ in the amount of blue content and in average position and amount of green contrast. Patterns that cannot be distinguished by these inputs are quite hard to find (Figures 12, 15A and B), but their existence shows that bees have no generally applicable means of distinguishing the layout of two colors in patterns subtending up to $55^{\circ}$, let alone more complex patterns.

\section{Reversal of black and white was recognized by retinotopic green modulation}

As a final example, a new group of bees easily discriminated between a white square on a black border and a black square of the same area on a white border (Figure 16A). There were equal areas of black and white on each target. These targets were equal in total brightness and color content, but the bees rapidly found a difference. Tests with each training target versus plain gray showed that the trained bees preferred to go to the greater contrast (Figure 16B and C). The trained bees failed to distinguish the patterns when equiluminant to the green receptors (Figure 16D), but with patterns equiluminant to the blue receptors, they preferred the one with more green contrast at the outer edges (Figure 16E). Finally, they preferred the vertical black bars at the extreme edges (Figure 16F). In this experiment, the bees used the green contrast at the outer edges (arrows), not the pattern or color difference.

\section{Forgotten anomalous data}

In his experiments 1 to 5 von Frisch ${ }^{1}$ trained his bees on a medium-gray paper and tested them on the whole series of gray levels displayed together in a tight square laid flat on tables outdoors, with different backgrounds. He found that bees trained on medium gray landed fairly equally across the gray series numbered from 0 (white) to 30 (black), with some preference for gray levels 10, 14, and 19 (Figure 17A). The bees did not distinguish the gray levels, not because they could not but because they had learned an average blue content and green modulation from the whole display square. In contrast, when trained on black or white, they landed near the appropriate end of the gray series, showing that they distinguished them from background. Von Frisch had no explanation; he gave up testing on the gray level series and turned to training on one color mixed with various gray levels.

Bees trained on blue or yellow among gray levels distinguished well between the training color and all shades of gray. However, when trained on green or blue-green near 


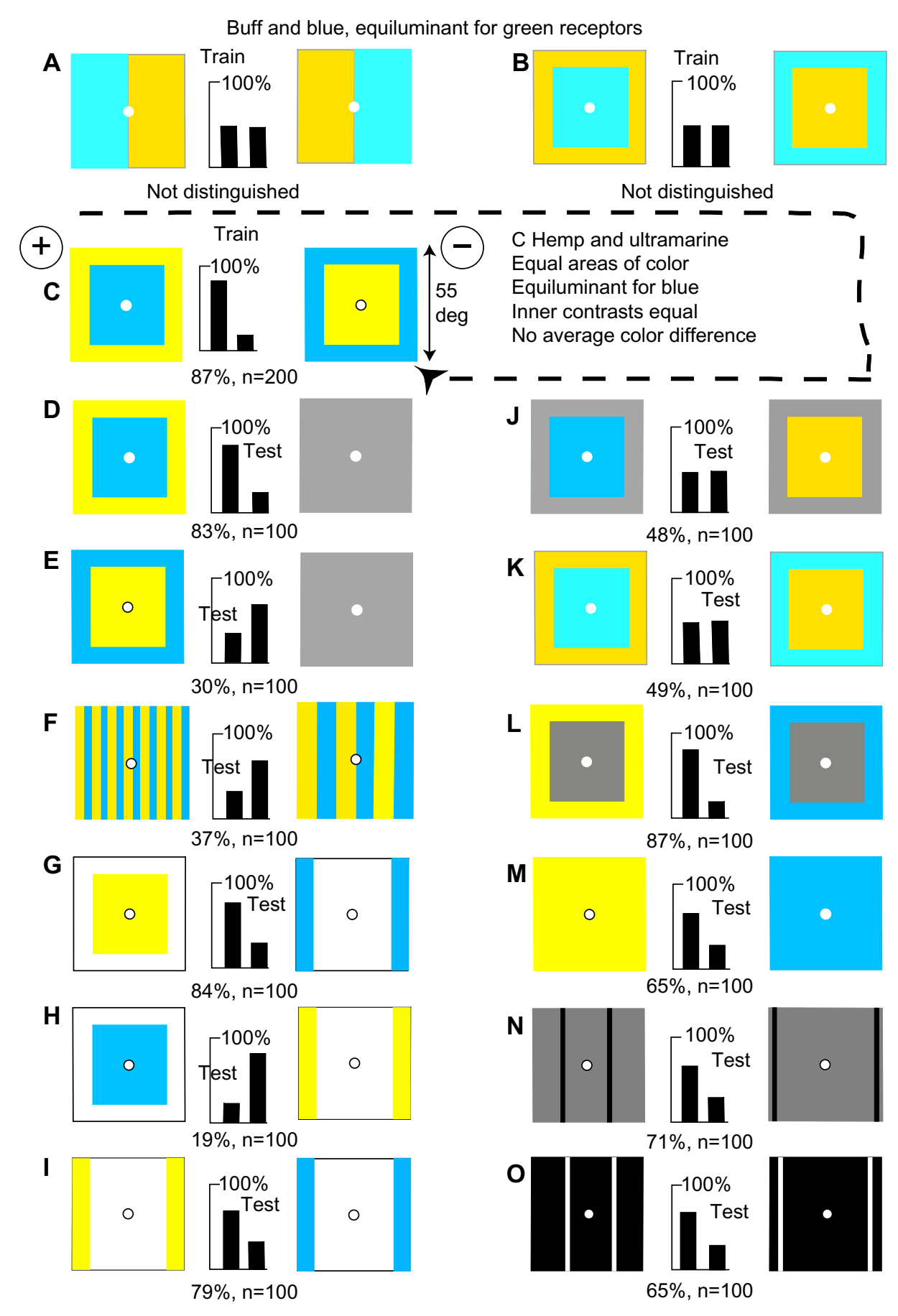

Figure 15 Discrimination of patterns of two colors required green contrast at vertical edges.

Notes: (A and B) These four patterns, equiluminant for the green receptors, were not distinguished by bees. (C) Bees readily distinguished this pair of patterns, which were equiluminant for the blue receptors. (D and E) The trained bees distinguished both training patterns from plain gray ( $40 \%$ black). They avoided the grating with more green contrast. (F) They avoided the greater green contrast. (G-I) They avoided vertical edges of ultramarine. (J and $\mathbf{K})$ With a gray surround or with no green contrast, recognition was lost. (L) The surrounds were distinguished despite the equal gray centers. (M) The isolated colors were distinguished. ( $\mathbf{N}$ and $\mathbf{O})$ They avoided the outer edges of green contrast more than the internal edges.

the middle of their spectral range, they performed badly and sometimes disastrously. This is not surprising because they had trained on a color with similar blue content to the background. Trained on blue-green (Figure 17B), they landed on number 6 in the gray series twice as often as on the blue-green paper (650 times compared with 306 times). Trained on green (Figure 17C), they landed on black. Again, von Frisch had no explanation; he gave up this type of experiment and turned to training on one color among a mix of colors and gray levels, and to testing on a range 

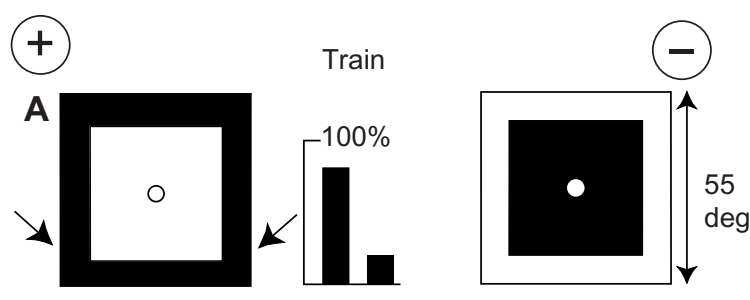

$89.0 \%, n=200$
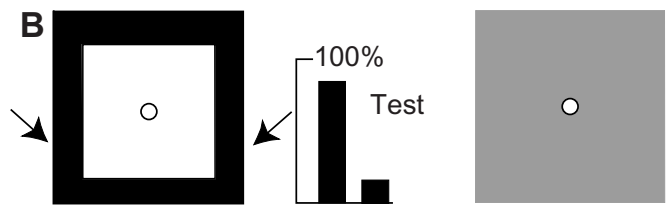

C

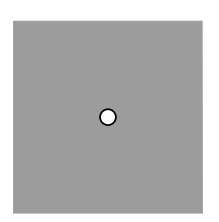

$84.5 \%, n=200$

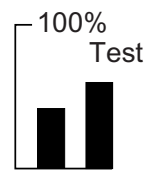

$40 \%, n=100$
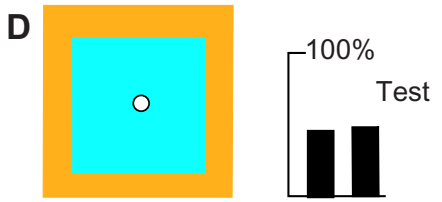

$48.5 \%, n=200$
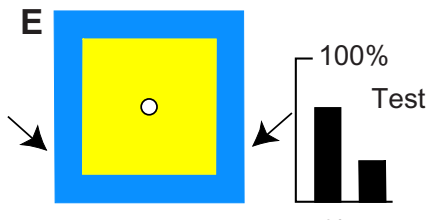

$65.5 \%, n=200$

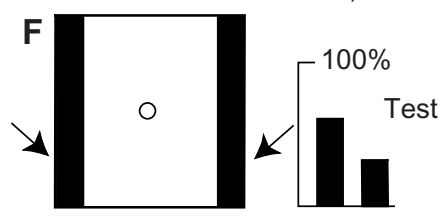

$63 \%, n=100$

Figure 16 White on black was discriminated from black on white (with no color difference) by the width between outside edges (arrows).

Notes: (A) Training patterns. (B and C) Memory was mainly of the rewarded target. (D) With no green contrast, the bees were lost. (E and F) With targets equiluminant for blue receptors or black bars on white, the vertical edges were still discriminated (arrows).

of colors (where the colors all had different levels of blue content).

His successes can perhaps be explained by different levels of blue content and green modulation. The failures to discriminate can be explained by considering the rapid adaptation to the background and the way bees distinguish colors and gray levels by their average blue content and measures of modulation at edges. In the bee maze (Figure 1), green was detected like any other color (Figures 6 and 11). ${ }^{3}$
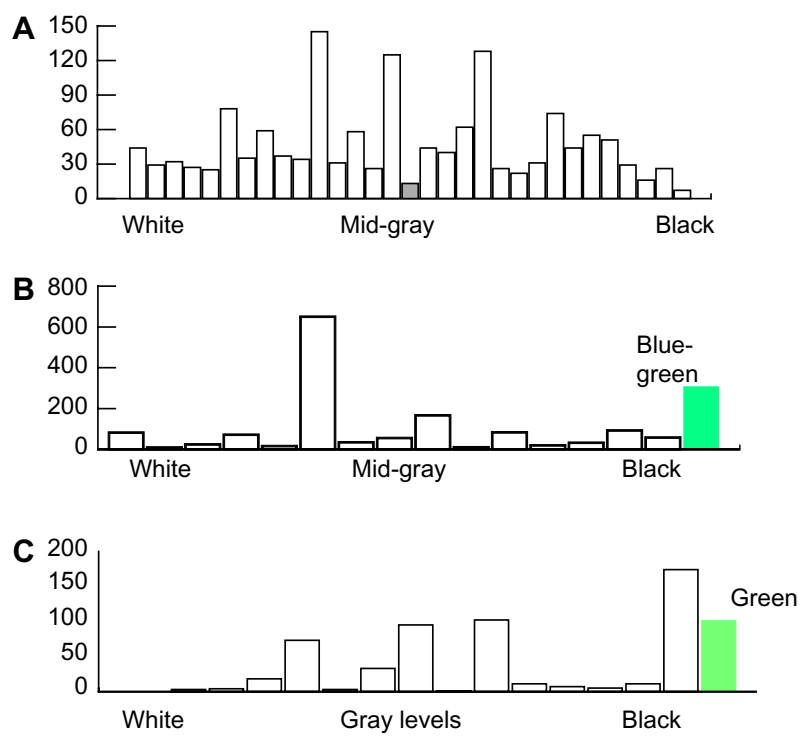

Figure 17 Forgotten anomalous data.

Notes: (A) Totals summed from von Frisch's tables I to 5.' The bees were trained for 9 days on medium-gray paper and tested on the gray series from white to black. The numbers of bees landing on the gray papers were distributed across the whole range, with a greater preference for particular papers near the middle of the range. (B) Totals summed from von Frisch's tables of results 72-79. The bees were trained on blue-green (number $\mathrm{II}$ in the Hering color series) and tested on the gray levels with blue-green added. (C) Totals summed from von Frisch's tables 69-7I. The bees were trained on green (number 10) and tested on the gray levels with green added. They preferred black or some medium grays. When trained on black, white, yellow, or blue, the bees behaved as expected.

\section{Discussion}

The training patterns in these experiments were selected to be as varied as possible and to include patterns that were equiluminant for green or blue receptors, as well as targets of plain black, white, or shuffled gray levels, and colored gratings (Table 2). Despite the great diversity of experiments, ${ }^{7}$ there was no example that could be construed to show human-like color vision. All illustrate the same few inputs used by the bees, namely, the difference in blue content, the measure and location of the modulation of the green receptors, and blue modulation when the others were unavailable (Table 2). When two displays were equiluminant for the blue receptors, the bees located and measured angular widths between vertical edges of green contrast. ${ }^{8}$ The preferred inputs were the strongest signals.

Blue was summed over a large field up to $55^{\circ}$ and maybe over the whole of each eye, but when green contrast was present as a landmark, bees distinguished a blue panel on the left of the reward hole from one on the right, so the two eyes summed separately. ${ }^{7}$ Memories of blue areas were averages of large areas but still retinotopic. Memories of blue modulation (Figure 13) and green modulation were strictly retinotopic (Figures 8-10, 15, and 16).

The bees adapted to the blue content of the white background in the apparatus, and they responded vigorously to 
Table 2 A summary of the inputs to the blue and the green receptor pathways in all of the experiments

\begin{tabular}{|c|c|c|c|c|}
\hline Fig No & Display I & Display 2 & Action of the blue receptor & Action of the green receptor \\
\hline 2 & Narrow blue bar on black & Blue square on black & Blue content measured & Width of green contrast at black edges \\
\hline 3 & Narrow blue bar on black & Wide blue bar on black & Blue content measured & Width of green contrast at black edges \\
\hline 4 & Narrow hemp bar on black & Wide hemp bar on black & Nil. No blue difference & Width of green contrast at hemp edges \\
\hline 5 & Black & Blue & Blue content & Width of black \\
\hline 6 & Green & Black & Little effect & Width of black \\
\hline 7 & Buff on black & Blue on black & Blue content & Nil. No green difference \\
\hline 8 & Buff on gray & Blue on gray & Blue content and blue contrast & Nil. No green difference \\
\hline 9 & Ultramarine & Hemp & Nil. No blue difference & Width of green contrast at ultramarine edges \\
\hline 10 & Buff & Ultramarine & Blue content & Width of green contrast at ultramarine edges \\
\hline II & Green & Black/white/gray shuffled & Avoids blue content in gray/white & Avoids green contrast at gray/black edges \\
\hline 12 & $\begin{array}{l}\text { Fine grating, no green } \\
\text { contrast }\end{array}$ & $\begin{array}{l}\text { Coarse grating, no green } \\
\text { contrast. Same blue content }\end{array}$ & Blue contrast only was measured & Nil. No green difference \\
\hline 13 & $\begin{array}{l}\text { Horizontal grating, } \\
\text { no green contrast }\end{array}$ & $\begin{array}{l}\text { Vertical grating, no green } \\
\text { contrast }\end{array}$ & Blue contrast only, retinotopic & Nil. No green difference \\
\hline 14 & Hemp/white grating & Blue/white grating & Avoids blue content in blue/white & Avoids green contrast in blue/white \\
\hline 15 & $\begin{array}{l}\text { Ultra on hemp } \\
\text { background }\end{array}$ & $\begin{array}{l}\text { Hemp on ultra } \\
\text { background }\end{array}$ & Nil. No blue difference & $\begin{array}{l}\text { Measures width between vertical edges } \\
\text { with green contrast }\end{array}$ \\
\hline 16 & White on black & Black on white & Nil. No blue difference & $\begin{array}{l}\text { Measures width between vertical edges } \\
\text { with green contrast }\end{array}$ \\
\hline
\end{tabular}

Note: Despite the wide range of patterns and colors presented, the bees used the same algorithm to make each discrimination with one or two cues.

Abbreviation: Fig No, figure numbers.

this when white was unexpectedly presented at a place where black or yellow was removed. ${ }^{3}$ These conclusions are logical deductions from the data, not intuitive leaps of preconceived notions that are compatible with the results but derived from other visual systems.

Bee visual mechanisms have style and simplicity - style to fit their life style and simplicity for speed of response and neuron economy. Their memory of a sequence of places and recognition of a target, crowded into a minute brain light enough to fly, enables them to find food and return for more. The principles are simple but subtle. Green and blue channels adapt separately, causing modulation and apparent blue content to change. Content of blue either greater or less than the average for the background is measured. The bees remember relative values of monochromatic blue content relative to background, a relation that does not change when the color or intensity of the ambient light changes. When flying in and out of green canopy, blue receptors are less influenced than green ones. Bees also measure the modulation locally in the green receptor pathway, measure angles between vertical edges, and triangulate using the angle between blue content and green modulation. The direction of contrast at a boundary edge is not detected because the edge detectors are symmetrical. ${ }^{3,7}$ Colors are therefore not even located or separated (Figure 15A and 15B). ${ }^{3,7}$ Pattern layout was of no interest, simply not detected. Total blue content and vertical edges were detected and learned retinotopically.
With reference to earlier work, ${ }^{12}$ there was no evidence that green content of targets was measured or related to blue content. With discriminations of green versus black (Figure 6), or green versus white, ${ }^{3}$ the usual inputs were used. The bees adapted to a background of white, green, or brown, then located color on a blue-yellow continuum by measuring blue content with large-field detectors. The green/ brown background was averaged and "adapted away" until only outstanding peaks of modulation remained, so the mass of information in the panorama was mostly ignored. Motion for flight control is detected through other green receptor phasic channels. ${ }^{10}$

We know very little about the UV channel. One observation is relevant - UV inhibits the effect of blue content in white. ${ }^{13}$ That implies a peculiar form of color vision but is exactly as expected from the inputs to mutually antagonistic neurons with inputs from blue and UV receptors. In other words, research on the UV channel will produce discoveries of simple algorithms that detect combinations with simple UV inputs, and lead farther away from trichromatic estimation of color.

Because colors were discriminated, we can define it as a form of color vision but not as trichromatic or color space as previously imagined. We might define the ratios of the green, blue, and UV modulations at a particular place as a measure of color because the temporal derivatives of three variables have the same ratios as the intensities themselves. In this case, the color for the bee would vary with image structure 
as well as spectral content, but there is no experimental indication of that.

Monochromatic signals necessarily enjoy lower relative noise than a contrast, in which one signal is subtracted from another. Using chromatic contrast would reduce the signal without reducing noise. Reliance on a monochromatic channel in relatively large fields and a different monochromatic channel with small fields is the best way to detect objects such as flowers on a background, especially if the background is continually "adapted out". Use of blue content makes use of photons with higher energy than those in the green part of the spectrum. When feeding, the blue channel locates objects by detecting greater or less blue content than green in large angular fields that reduce noise, while numerous small-field green channels detect landmarks, unusual motion, and optic flow, to stabilize the eye, control the flight path, and measure range from angular velocity and size. ${ }^{10}$

A monochromatic channel is also an advantage when the color of the ambient illumination changes. With monochromatic vision, inserting a filter in the path or changing the illumination color leaves the ratios of inputs exactly as they were before the change. The very rapid and 1,000-fold range of adaptation of the bee eye (tenfold in 2 minutes) ${ }^{14}$ quickly brings sensitivity to where it was before the change.

In general, when bees were trained with a sequence or a selection of several colors or patterns placed together, they adapted to the average or a common factor then detected cues, not colors. This led von Frisch ${ }^{1}$ astray. In an early experiment, he trained on a medium-gray paper placed among a gray series, but his trained bees were then unable to recognize the training paper (Figure 17A). When he trained on black or white and tested on the gray series, his bees performed normally. When he trained on blue-green or green among a gray series, the trained bees confused the colors with medium gray (Figure 17B and C), but the same bees discriminated yellow or blue from a gray series. The explanation is that the bees had learned the average blue content of gray papers that were packed into a square, which became a background. The bees could have detected the color by blue or green contrast. Similarly, flowers are noticed by blue content differences and green modulation relative to background.

No apology is needed when new facts interfere with old beliefs, and we now look forward to a testing of many beliefs about color vision in bees. It is clear that 100 years of conclusions need serious revision because they were based on incorrect theory.
Finally, it should be emphasized that these experiments tell us nothing about mechanisms of learning, how bees make choices, or how they organize a sequence of landmarks. Once we get beyond reporting the bee's remarkable performance, much remains to be done with experimental analysis of these behavior patterns. Bees are available worldwide, training bees is inexpensive, does not need a laboratory, and is suitable for all ages.

\section{Acknowledgments}

The author thanks Mr Richard Johnston (Canberra Beekeepers Association) for the loan of a hive of bees, and Professor M Srinivasan for help with calibrating the reflection spectra of the colored papers in sunlight.

\section{Disclosure}

The author reports no conflict of interest in this work.

\section{References}

1. von Frisch K. Der Farbesinn und Formensinn der Bienen [The color and shape sense of bees]. Zoologisches Jahrbucher Physiologie. 1914;35(1): 1-188. German.

2. Hess C. Beiträge zur Frage nach einen Farbensinne bei Bienen [Review of the question of color vision in bees]. Pflügers Arch Gesamte Physiol Menschen Tiere. 1918;170(7-9):337-366.

3. Horridge A. How bees distinguish black from white. Eye and Brain. 2014;6(1):9-17.

4. Horridge GA. Visual resolution of gratings by the compound eye of the bee Apis mellifera. J Exp Biol. 2003;206(Pt 13):2105-2110.

5. Horridge GA. Pattern vision of the honeybee (Apis mellifera): the effect of pattern on the discrimination of location. J Comp Physiol A. 1999;185(1):105-113.

6. Srinivasan MV, Lehrer M. Spatial acuity of honeybee vision and its spectral properties. J Comp Physiol A. 1988;162(2):159-172.

7. Horridge A. How bees distinguish a pattern of two colors from its mirror image. PLoS 1. 2015;10(1):1-23.

8. Horridge A. Pattern vision of the honeybee (Apis mellifera): blue and green receptors in the discrimination of translocation. Neurobiol Learn Mem. 2000;74(1):1-16.

9. Friedlaender M. Zur Bedeutung des Fluglochs im optischen Feld der biene bei senkrechter Dressuranordnung. [The significance of the reward hole in the optic field of bees trained on vertical targets]. Z Vergl Physiol. 1931;15(2):193-260. German.

10. Horridge A. What does the Honeybee See? And How Do We Know? Canberra: ANU Press; 2009. Available from: http://epress.anu.edu.au/ honeybee_citation.html. Accessed January 5, 2015.

11. Lubbock J. Ants, Bees and Wasps. London: Kegan Paul; 1881.

12. Chittka L. Bees, white flowers, and the color hexagon - a reassessment? No, not yet. Naturwissenschaften. 1999;86(12):595-597.

13. Hertz M. New experiments on color vision in bees. J Exp Biol. 1939; 116(1):1-8.

14. Wolf E, Zerrahn-Wolf G. The dark adaptation of the eye of the honey bee. J Gen Physiol. 1935;19(2):229-237. 
Eye and Brain

Dovepress

\section{Publish your work in this journal}

Eye and Brain is an international, peer-reviewed, open access journal focusing on clinical and experimental research in the field of neuro-ophthalmology. All aspects of patient care are addressed within the journal as well as basic research. Papers covering original research, basic science, clinical and epidemiological studies, reviews and and extended reports are welcome. The manuscript management system is completely online and includes a very quick and fair peer-review system, which is all easy to use. Visit http://www.dovepress.com/ testimonials.php to read real quotes from published authors.

Submit your manuscript here: http://www.dovepress.com/eye-and-brain-journal 